\title{
An Experimental and Numerical Study on Acoustic Emission in the Process of Rock Damage at Different Stress Paths
}

\author{
Dongxu Liang $\mathbb{D}$, Nong Zhang $\mathbb{D}$, and Haoyu Rong $\mathbb{C}$ \\ Key Laboratory of Deep Coal Resource Mining, Ministry of Education of China, School of Mines, China University of Mining \\ \& Technology, Xuzhou, Jiangsu 221116, China
}

Correspondence should be addressed to Nong Zhang; zhangnong@cumt.edu.cn

Received 24 June 2021; Accepted 24 July 2021; Published 9 August 2021

Academic Editor: Afshin Davarpanah

Copyright ( 2021 Dongxu Liang et al. This is an open access article distributed under the Creative Commons Attribution License, which permits unrestricted use, distribution, and reproduction in any medium, provided the original work is properly cited.

\begin{abstract}
The study of the damage process of rock under external loads is good guidance for geotechnical construction design. The differences in rock damage processes and damage modes under different stress paths are rarely reported. To explore the effects of stress paths on rock damage processes, uniaxial compression experiments under three stress paths were conducted. Numerical simulation is also used to simulate the rock acoustic emission (AE) and fracture process. The results of the study indicate that the maximum acoustic emission events are at the peak of stress, and fractures are mainly formed at this stage. The peak of AE energy occurs before the peak of AE events. The damage pattern and fragmentation size of the rock are related to the way the stresses are loaded. It is noticed that there is appearance of a quiet period of AE events prior to the production of significant cracks. Minor damage to the rock is accompanied by the generation of bright white spots in the specimen, which is due to the high tensile or shear stress in the units. When the stress in these units exceeds their strength, the units break down and tiny cracks appear. As the external load increased, the cracks developed and penetrated, and the specimen was damaged. Under cyclic loading and unloading, the number of $\mathrm{AE}$ events increased significantly compared with the controlled displacement and controlled stress loading methods, and the radius of the AE circle became larger and the energy also increased, which indicates a greater degree of destruction of the rock under cyclic loading and unloading. The results of the study are of reference significance for rock crack propagation and fracture mode influenced by stress conditions and provide some guidance for construction design under different working conditions.
\end{abstract}

\section{Introduction}

Destabilization damage to rock plays an important role in the field of engineering geology, such as underground mining, petroleum engineering, and slope engineering. At the same time, the cracks produced during rock fracture have a great influence on the permeability of the rock, causing a fluid flow in underground rock, especially for fluid flow in oil and gas reservoirs. Understanding the rock damage process and its damage mode is very informative for geotechnical and oil and gas extraction engineering.

Deformation and damage will occur when the rock is subjected to external loads, which is a process of the rock from the development of tiny damage in the intact medium to the formation of macroscopic cracks and eventually leading to global fracture. Many scholars have done a lot of research on this. In order to investigate the complete stressstrain and damage evolution behavior of brittle rocks [1], acoustic emission experiments are widely used as an effective monitoring tool in laboratory experiments and field tests. Bruning et al. [2] conducted a series of triaxial compression tests on granite buried at depths greater than $1000 \mathrm{~m}$ to determine stress thresholds for crack initiation, coalescence, and damage. Xu et al. [3] conducted a series of uniaxial compression tests and cyclic loading tests on sandstone samples and the results showed that the ratio of maximum stress and stress amplitude to uniaxial compressive strength is the most important factor affecting the fatigue life of sandstone.

Liu et al. [4] used an acoustic emission localization technique and performed shear experiments to obtain the distribution mode and distribution characteristics of the cracks. Odegaard and Nilsen [5] proposed a simplified and cost- 
effective method for measuring the minimum principal stress in the tunnel and using acoustic emission (AE) data to interpret fracture behavior and evaluate fracture normal stresses. With the aim of gaining a deeper understanding of the relationship between rock fracture and fracture scale, Shengxiang et al. [6] investigated the correlation between rock breakage mechanism and the characteristic parameters of acoustic emission (AE) signal under splitting load. The attempt of a $\mathrm{CO}_{2}$ hydraulic fracturing acoustic emission monitoring experiment [7] provides implications for the use of carbon dioxide $\left(\mathrm{CO}_{2}\right)$ to recover geothermal energy and shale gas. Fluid penetration leads to rock dilatation and fracture. Zhou et al. [8] conducted several sets of cracking tests in different initial states using a self-made device, and the results of the study showed that the internal structure of the rock was damaged under the combined effect of swelling stress and softening effect, leading to the generation and development of cracks. The mechanical mechanism of crack generation and the shape of the generated cracks can be different due to different reasons for uneven swelling.

Cyclic loading [9] is often a common operating condition on engineering sites. Liang et al. [10] conducted laboratory experiments on sandstone with equal amplitude and graded cyclic loading and unloading under uniaxial compression and obtained damage evolution trends. Temperature also has a large effect on rock fracture. Wang et al. [11] studied the deterioration mechanism and fatigue fracture evolution of granite with two preexisting defects treated with freezethaw (FT). Sun et al. [12] used a combined infrared radiation (IR) and acoustic emission (AE) monitoring system for analyzing the acoustic and thermal effects during rock damage under uniaxial compression. The results showed that there were acoustic and thermal time-related effects during the damage to the rocks. It is well known that the creep properties of rocks are an unfavorable factor for the long-term stability of underground structures. Zhao et al. [13] carried out a series of creep tests to determine the relationship between the wave characteristics of acoustic emission signals and the length of microcracks in rock, and the wave characteristics of acoustic emission signals at different creep stages were considered from the perspective of elastic wave dynamics. The strength and damage characteristics of rocks under different stress paths are different. Lu et al. [14] studied the deformation, strength, and damage characteristics of soft sandstone and raw coal under two different true triaxial loading paths using a self-developed true triaxial test apparatus. Kharghani et al. [15] probed the effect of anisotropy on the Kaiser effect of rocks. Uniaxial compression tests and Brazilian tensile strength tests were performed on rock specimens with various anisotropic angles (0,30, 60, and 90 degrees) to obtain their acoustic emission effects. The mechanical properties and fracturing behavior of coal bodies cannot be neglected for the safety and stability of underground mining. Li et al. [16] applied dynamic loading coupled to biaxial static and dynamic tests on coal specimens at five laminar directions and four impact velocities. A positive correlation was obtained between the velocity of coal injection and loading rate, and the average fragment size of coal samples was negatively correlated with impact velocity and energy absorp- tion. Rock burst disasters and fluid-induced earthquakes occur frequently during coal mining, and microseismic monitoring is often used to monitor rock bursts or to provide early warning [17-21], showing good results. Fracture extension studies in rocks are important for assessing the ability of coal seams to form fracture networks by hydraulic fracturing for the development of coal bed methane (CBM) reservoirs [22] and drilling engineering for the petroleum industry [23]. To find out the determinants of hydraulic fracture extension and associated rock damage mechanisms, laboratory hydraulic fracturing experiments under triaxial stress were conducted to research this effect [24]. However, although there are many previous research results on rock fracture processes, the response of acoustic emission characteristics of rock damage under different stress paths and the influence of stress paths on damage modes have rarely been reported.

In the past decades, numerical computational methods have been widely used in rock mechanics problems. Nowadays, there are various numerical analysis methods that can be applied to rock mechanics, and the main methods include (1) finite element methods, such as Phase2D; (2) boundary element methods, such as Examine; and (3) discrete element methods, such as UDEC and PFC. However, the finite element method and the boundary element method are computational methods based on the mechanics of continuous media, which makes this method limited in its scope of application. The discrete element method highlights its advantages when analyzing the mechanics of rock fracture processes $[25,26]$. So far, there is no mature simulation software that can better study the process of transforming rock masses from continuous to discontinuous media under the action of loads. In order to solve the problems of nonlinearity of geotechnical materials, the influence of fractures, joints in rock masses and discontinuous surfaces on calculation results, and the influence of stepwise excavation and filling construction operations on the stability of surrounding rock, Tang [27] proposed a new numerical simulation method "Realistic Failure Process Analysis (RFPA)" method, which takes into account the characteristics of nonhomogeneity, discontinuity, and anisotropy of rock media. The RFPA code can be used to analyze the deformation and damage to rock specimen loading, acoustic emission of rock, deformation and damage to brittle materials such as concrete, ground sinking, rock movement, damage to the roadway, roof fall, bottom slab sudden water, simulation and analysis of deformation and damage of ceramics and composite materials, gas-solid coupling analysis such as gas protrusion of coal and rock bodies, heat-solid coupling analysis in materials such as rock and concrete, slope stability simulation, and analysis. Rock rheology-solid coupling in hydraulic engineering, rock rheological characteristics' analysis, underground engineering excavation and support, and other issues for analysis and research were discussed. RFPA adopted a calculation method combining finite element theory and statistical damage theory. This calculation method takes into account the nonuniformity of the medium and the randomness of the defect distribution, takes the material properties into account using the knowledge of statistical distribution, and 
combines the finite element numerical calculation method with the damage treatment of the unit body according to the set strength criterion to complete the numerical simulation of the damage process of nonuniform materials, which can solve the difficult problem of the fine rupture process in geotechnical engineering with the RFPA code.

In this paper, by conducting uniaxial compression acoustic emission experiments on sandstone with different stress paths, parameters such as the number of acoustic emission events and energy captured by acoustic emission combined with stress-strain curves were analyzed, and the phenomenon of the AE events quiet period was found. Subsequently, a numerical simulation method was used to simulate the acoustic emission localization and fracture damage process for uniaxial compression experiments under different stress paths, and the simulation results were in high agreement with the experimental results. Finally, the influence of stress paths on the final damage mode of the rock is discussed.

\section{Laboratory Experiments}

In order to study the characteristics of AE during uniaxial compression damage to rocks under different stress paths, laboratory experiments were conducted, and the stressstrain curves, the number of $\mathrm{AE}$ events, and the energy parameters under different paths were analyzed.

2.1. Preparation of Rock Specimens. The rock specimens were standard cylindrical specimens of $100 \mathrm{~mm} \times 50 \mathrm{~mm}$ in size, which were prepared by drilling from the natural rock mass of sandstone in strict accordance with the method recommended by the International Society of Rock Mechanics [28]. A total of 14 rock specimens were made, as shown in Figure 1. Five of them were used for uniaxial compression experiments and shear experiments to obtain the basic mechanical parameters (including uniaxial compressive strength, modulus of elasticity, density, and angle of internal friction), and the basic physical-mechanical parameters obtained by averaging are shown in Table 1 . Three experiments were conducted for each of the three different stress paths (described in detail in Section 2.2).

2.2. Experimental Apparatus and Loading Scheme. The uniaxial compression experiments were performed on the MTS-816 electrohydraulic servo tester, which can be programmed to control the displacement and stress loading, and the equipment automatically records the load and displacement and stores them on the computer. During the loading process, four acoustic emission probes were attached to the rock surface. The acoustic emission probes were connected to the acoustic emission signal acquisition device through an amplifier. The amplifier parameters were set to $40 \mathrm{~dB}$, the acquisition frequency was set to $3 \mathrm{MHz}$, and the minimum amplitude was set to $20 \mathrm{mV}$. All the experimental equipment was connected as shown in Figure 2. The experimental system consists of two parts: the loading system and the AE monitoring system.

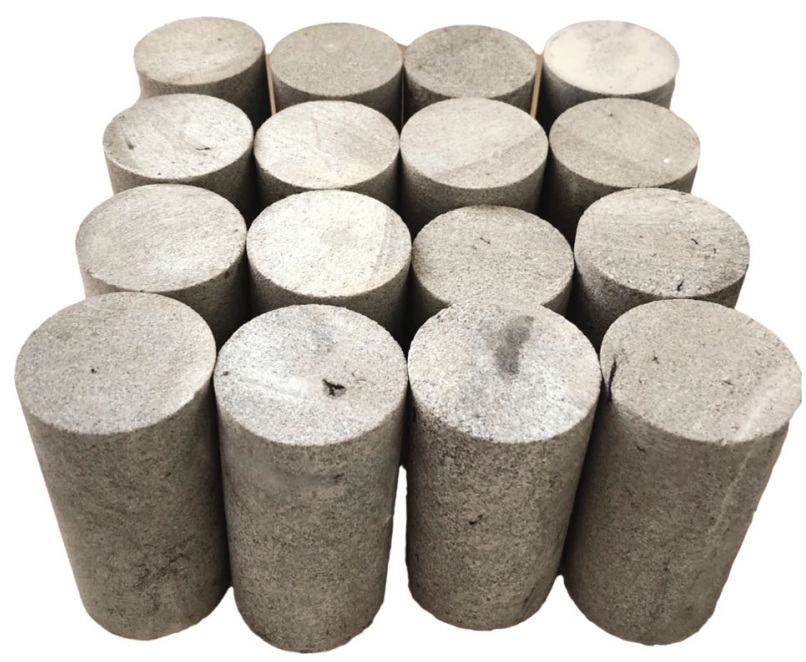

Figure 1: Rock samples.

Three experiments were conducted for each loading scheme under the three stress paths. The three loading scenarios are shown in Figure 3, respectively.

(1) Loading by means of controlled displacement loading, with axial loading at a displacement rate of $0.002 \mathrm{~mm} / \mathrm{s}$, and one loading until the specimen is destroyed (as shown in Figure 3(a))

(2) Loading by means of controlled stress loading, with a stress loading rate of $0.5 \mathrm{kN} / \mathrm{s}$, once loaded until the specimen is destroyed (as shown in Figure 3(b))

(3) Cyclic loading and unloading by means of controlled stress loading, with a stress loading rate of $0.5 \mathrm{kN} / \mathrm{s}$ (as shown in Figure 3(c))

\section{Experimental Results}

In this work, to study the damage and destruction of rocks during uniaxial compression, the experimentally acquired stress-strain curves, $\mathrm{AE}$ events, and $\mathrm{AE}$ energies were statistically analyzed.

\subsection{Acoustic Emission Law under Controlled Displacement} Loading Conditions. As can be seen from Figure 4, the AE events of the sandstone reached a peak in the pressuredense phase (near $0.08 \%$ strain) when the loading was carried out with controlled displacement. This was due to the dense structure of the sandstone, and after pressure loading, the original microfractures closed under the load and deformed, and the accumulated large amount of deformation energy was released to produce elastic waves. After entering the elastic stage, the AE events of the sandstone remained at a stable level, and the AE events were basically 0 , indicating that there was no substantial damage to the rock at this stage. When the strain reached $0.28 \%$, the sandstone entered the plastic stage, and the $\mathrm{AE}$ events increased abruptly and another peak (reaching 920) appeared. Accompanied by a small drop in stress, the $\mathrm{AE}$ event number decreased to close to 0 , then increased sharply again, after which it stabilized at a smaller 
TABLE 1: Basic physical and mechanical parameters of rock.

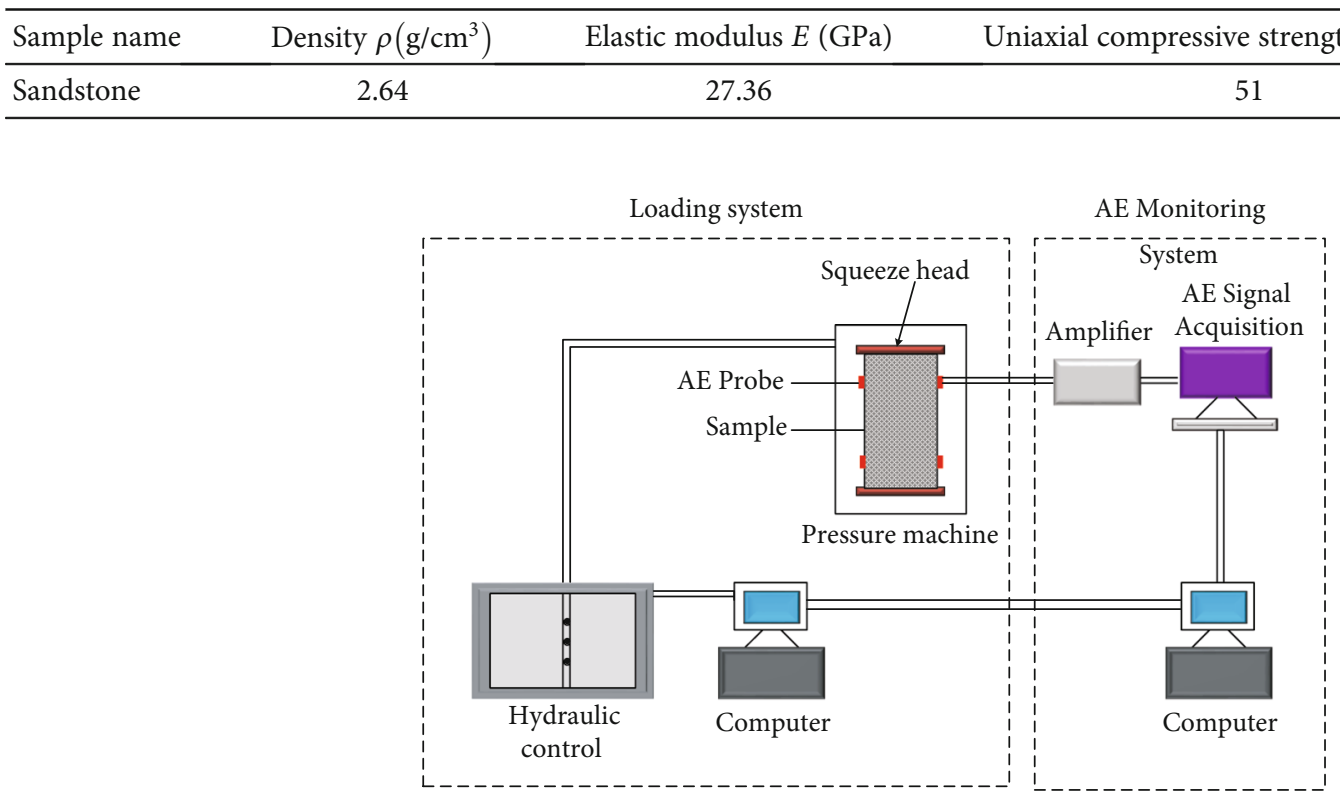

FIGURE 2: Experimental system connection diagram.

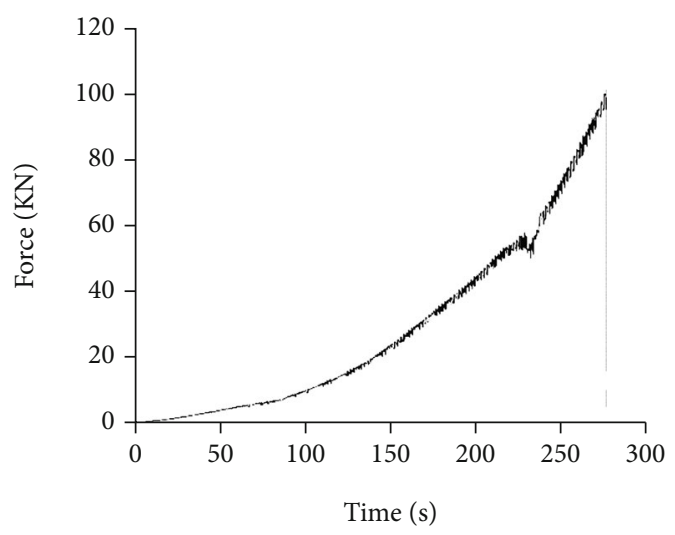

(a)

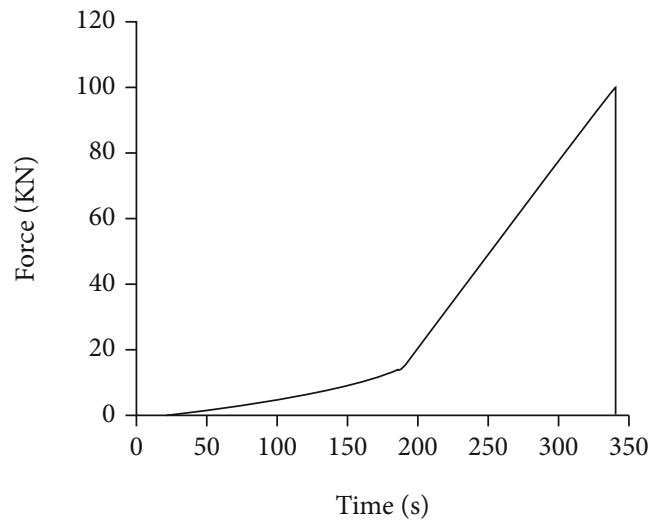

(b)

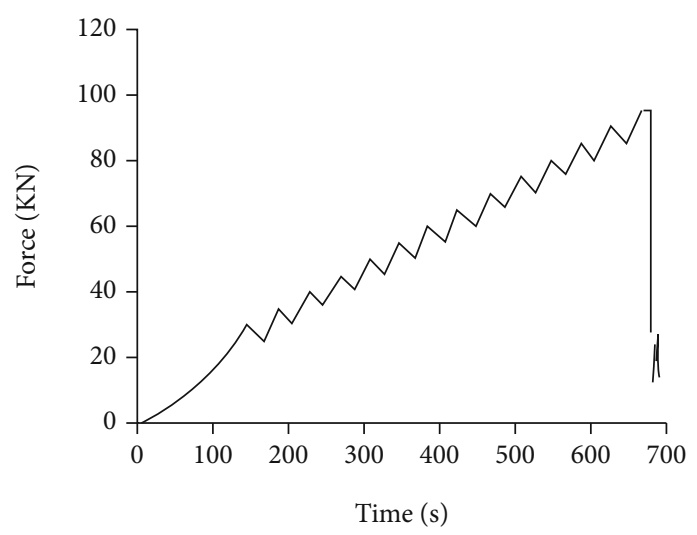

(c)

FIGURE 3: Loading scheme diagram: (a) controlled displacement loading, (b) controlled stress loading, and (c) controlled stress cyclic loading and unloading. 


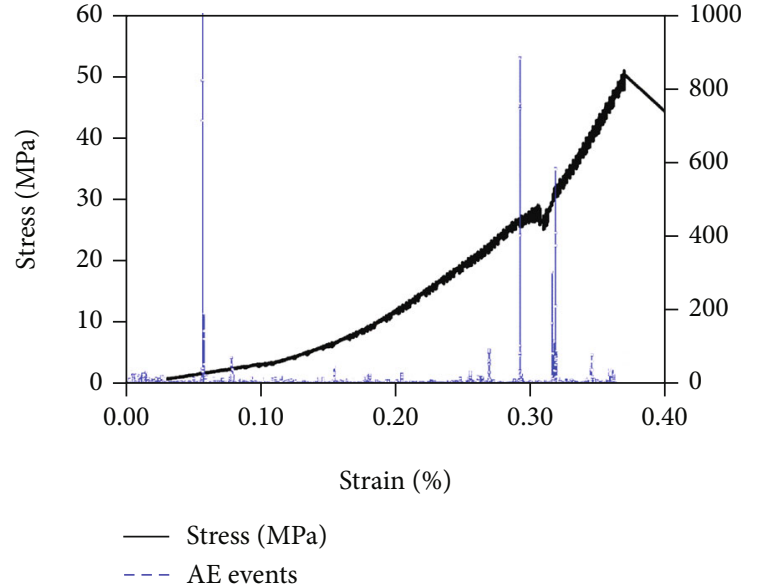

(a)

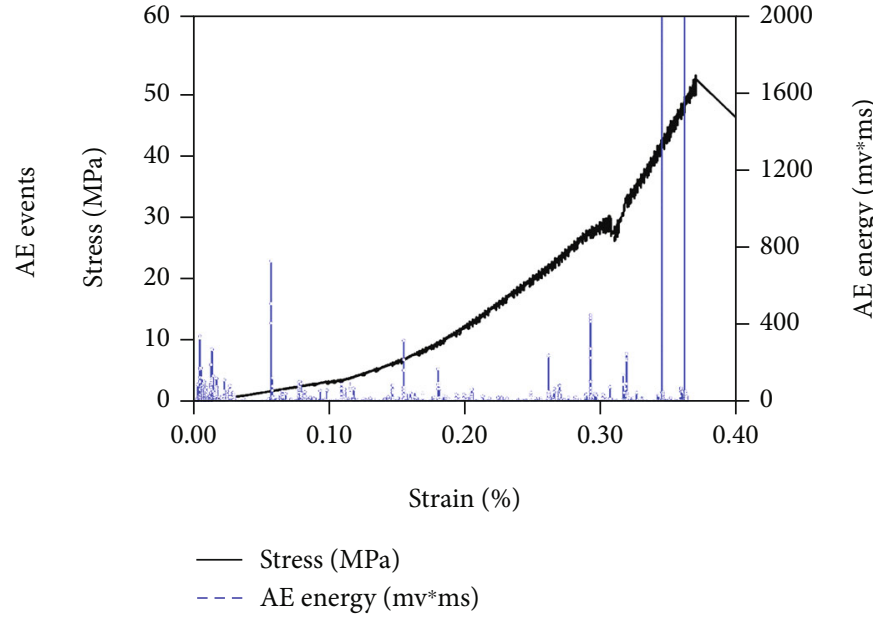

(b)

FIGURE 4: Diagram of AE parameters versus stress-strain for sandstone during controlled displacement loading: (a) AE events and (b) AE energy.

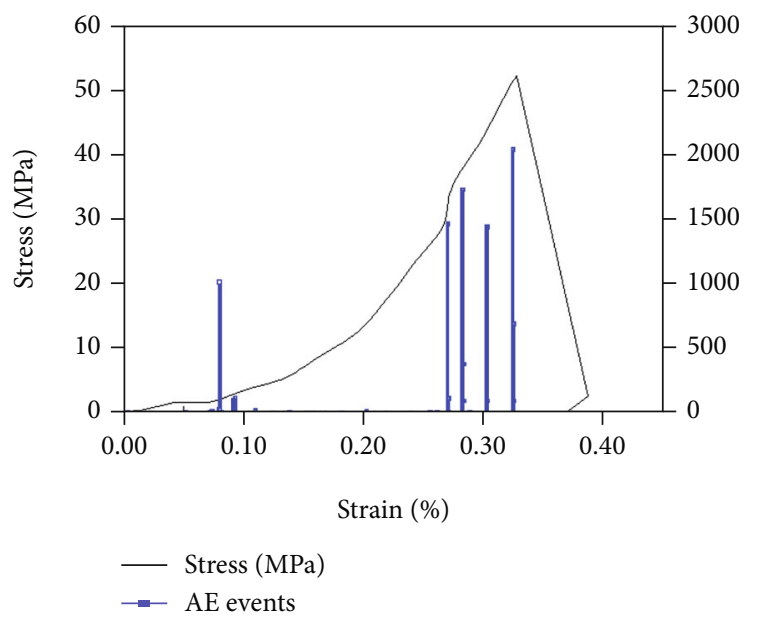

(a)

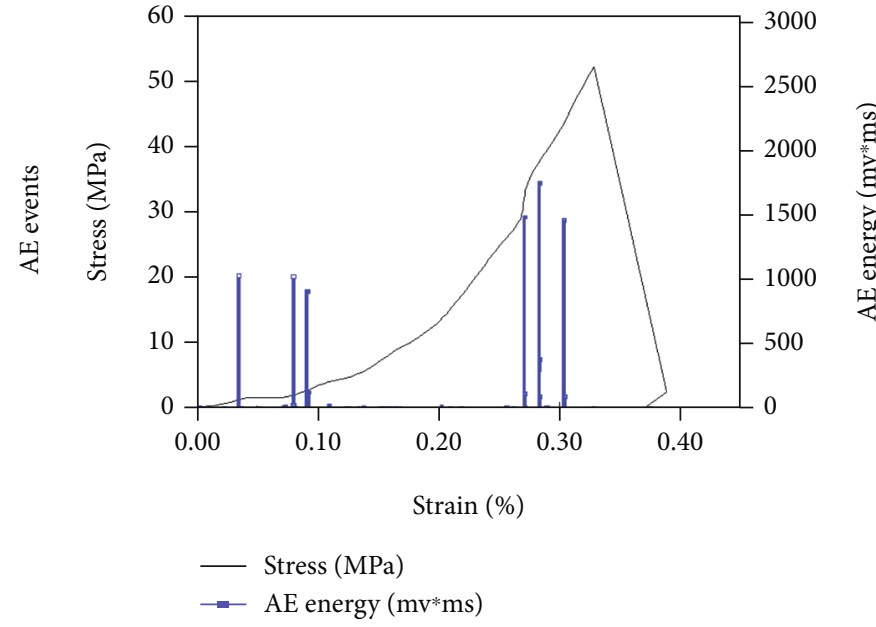

(b)

Figure 5: Diagram of AE parameters versus stress-strain for sandstone during controlled stress loading: (a) AE events and (b) AE energy.

value until a small increase before the peak stress. This indicates that the damage to sandstone was mainly in the plastic stage and completed most of the crack generation and expansion before the peak stress; i.e., the damage to the rock mainly occurred in the plastic stage, and the macroscopic damage after the peak stress was only a macroscopic presentation on the basis of the previous one. For the AE energy value, its trend was basically consistent with the $\mathrm{AE}$ events, but in the plastic stage, the $\mathrm{AE}$ energy value lagged relative to the $\mathrm{AE}$ events; i.e., the $\mathrm{AE}$ energy value was not maximum when the number of $\mathrm{AE}$ events was maximum.

\subsection{Acoustic Emission Law under Controlled Stress Loading} Conditions. It can be seen from Figure 5 that the whole $\mathrm{AE}$ events and AE energy values of the sandstone vary distinctly. At the end of the compressional stage, the $\mathrm{AE}$ events reached a peak, and the AE energy values had a sudden and significant increase at the beginning and end of the compressional stage. After entering the elastic stage, the $\mathrm{AE}$ events and $\mathrm{AE}$ energy values of the sandstone drop to zero, and the $\mathrm{AE}$ activity tends to calm down. At the boundary between elastic and plastic stages, $\mathrm{AE}$ events and $\mathrm{AE}$ energy values increase abruptly. Unlike the controlled displacement loading method, the $\mathrm{AE}$ events and $\mathrm{AE}$ energy values increased simultaneously after the rock entered the plastic stage when the controlled stress was loaded once, and there was no situation where the $\mathrm{AE}$ energy values lagged behind the increase in the number of $\mathrm{AE}$ events, so the $\mathrm{AE}$ events and $\mathrm{AE}$ energy values can be used as the precursor criterion for rock damage in this case.

3.3. Acoustic Emission Law under Controlled Stress Cyclic Loading and Unloading Conditions. Under the uniaxial cyclic loading and unloading conditions, the variation pattern of $\mathrm{AE}$ events in sandstone was consistent with the stress-strain curve of the rock. In the compression-dense phase, the 


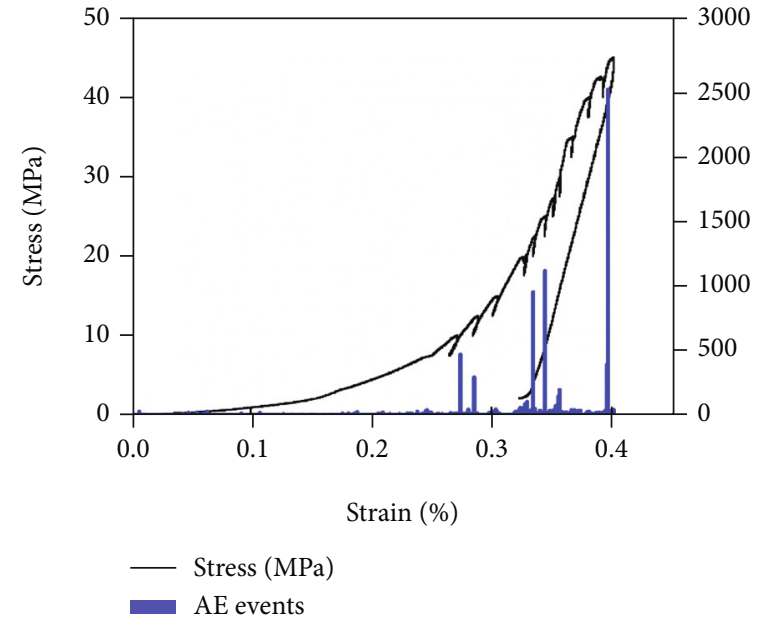

(a)

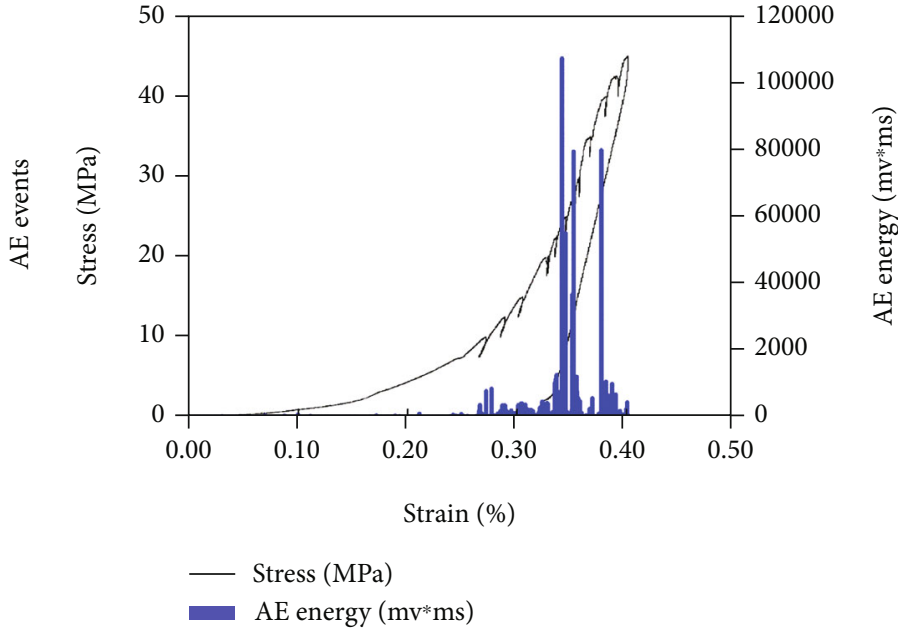

(b)

Figure 6: Diagram of AE parameters versus stress-strain for sandstone during controlled stress cyclic loading: (a) AE events and (b) AE energy.

sandstone was basically free of $\mathrm{AE}$ events as shown in Figure 6(a). When the stress increases, the sandstone lasts longer in the elastic phase, so the number of AE events tends to increase. In the late elastic stage, the AE events increased significantly. In the plastic stage, the cracks inside the rock gradually expanded and the damage intensified. The AE events increased significantly, the AE energy continued to grow, and the AE events increased abruptly when the peak stress was approached. This was due to the large number of new cracks generated at the peak stress, resulting in numerous acoustic emission points. From Figure 6(b), the peak energy of the sandstone was advanced compared to the peak $\mathrm{AE}$ events; i.e., the energy of the sandstone was not maximum when the $\mathrm{AE}$ activity was most intense. In the postpeak damage stage, after the peak stress, the sandstone showed fracture damage. The AE test ended. During the unloading process, the strain causes a rebound phenomenon. The AE event was basically 0 , and the energy value decreased abruptly and gradually converged to 0 .

\section{Numerical Simulation}

Numerical simulations were conducted using RFPA for sandstone with three different stress paths (displacement loading, stress loading, and cyclic loading and unloading) to compare with previous experiments and to study the acoustic emission characteristics under different stress paths.

4.1. Basic Theory of Simulating Acoustic Emission. In an effort to fully consider the deformation damage caused by the nonuniformity and discontinuity of the medium under external loading, three types of element were inserted into the RFPA system, namely, the matrix element, contact elements, and air element. The transformation of the three elements occurred when the strain reached a certain condition, which we called the phase transition, and the condition reached was called the phase transition point. So far, there is no unified understanding of how to properly select the phase transition critical point. Since rock materials are similar to brittle materials and their tensile strength is much less than their compressive strength, the RFPA system used the modified Coulomb criterion as the phase transition critical point of the primitive element. It can be expressed mathematically as [29]

$$
\left\{\begin{array}{l}
\sigma_{1}-\frac{(1+\sin \theta)}{(1-\sin \theta)} \cdot \sigma_{3} \geq \sigma_{c}, \sigma_{1} \geq \sigma_{c}\left(1-\frac{1+\sin \theta}{1-\sin \theta} \cdot \frac{1}{\lambda}\right) \\
\sigma_{3} \leq-\sigma_{t}, \sigma_{1} \leq \sigma_{c}\left(1-\frac{1+\sin \theta}{1-\sin \theta} \cdot \frac{1}{\lambda}\right)
\end{array}\right.
$$

where $\sigma_{c}$ is class I phase change threshold, $\sigma_{t}$ is class II phase change threshold, and $\theta$ is friction angle of the rock.

$\sigma_{c}=\lambda\left|\sigma_{t}\right|, \lambda$ is the ratio of tensile strength to compressive strength. It must be satisfied in this criterion that $\sigma \geq 0$, so only when

$$
\sigma_{1} \geq \sigma_{v}\left(\left(\sigma_{v}=\sigma_{c}\left(1-\frac{1+\sin \theta}{1-\sin \theta} \cdot \frac{1}{\lambda}\right)\right)\right) .
$$

The Coulomb criterion does not work, and the uniaxial tension criterion is applied in this case.

For discrete primitive bodies, their mechanical properties have a statistical distribution law, and the RFPA system uses the Weibull statistical distribution function to characterize the distribution law of the mechanical properties of the elements, which is expressed by the following equation.

$$
\varphi(\alpha)=\frac{m}{\alpha_{0}} \cdot\left(\frac{\alpha}{\alpha_{0}}\right)^{m-1} \cdot e^{-\left(\alpha / a_{0}\right)^{m}}
$$

where $\alpha$ is the mechanical parameter of the elements, $\alpha_{0}$ is the mean value of the mechanical properties of the elements, $m$ is 
TABLE 2: The numerical simulation test parameters of rock.

\begin{tabular}{lccccc}
\hline Sample name & Homogeneity & Elastic modulus $E(\mathrm{GPa})$ & Poisson's ratio $\mu$ & $\mathrm{UCS} \sigma_{\mathbf{c}}(\mathrm{MPa})$ & Angle of internal friction $\phi\left(^{\circ}\right)$ \\
\hline Sandstone & 3 & 27.36 & 0.3 & 51 & 35 \\
\hline
\end{tabular}

the shape parameter of the distribution function, and $\varphi(\alpha)$ is the statistical distribution density of $\alpha$.

There are only two states of the elements from the point of integrity, i.e., damaged and undamaged. In the undamaged state, the initial damage to the elements $D_{0}=0$. From Equation (3), the damage variable, expressed as a statistical distribution law of the strength of the material matrix, can be obtained as follows:

$$
D=\int_{0}^{\varepsilon} \varphi(x) d x \int_{0}^{\varepsilon}\left[\frac{m}{\varepsilon_{0}} \cdot\left(\frac{x}{\varepsilon_{0}}\right)^{m-1} \cdot e^{\left(E / E_{0}\right)^{m}}\right] d x=1-e^{-\left(E / E_{0}\right)^{m}}
$$

where $D$ is the damage variable of rock, $E_{0}$ is the average modulus of elasticity value of all elements of the matrix, and $E$ is the value of the modulus of elasticity of the element.

A combination of the Monte-Carlo method and statistical theory was used in the element assignment, and the Weibull function integral of the elastic modulus based on Equation (3) can be expressed as

$\phi(\mathrm{E})=\int_{i}^{j} \varphi(x) d x \int_{i}^{j}\left[\frac{m}{\varepsilon_{0}} \cdot\left(\frac{x}{\varepsilon_{0}}\right)^{m-1} \cdot e^{-\left(E / E_{0}\right)^{m}}\right] d x=1-e^{-\left(E / E_{0}\right)^{m}}$,

where $\phi(E)$ is the value of the distribution of the elements with the modulus of elasticity $E$.

With the progress of damage mechanics research, research on the theory of acoustic emission techniques has made remarkable breakthroughs. In 1990, Tang [29] proposed the hypothesis that acoustic emission of rocks is consistent with the damage to rocks based on the principle of statistical microscopic damage mechanics and the principle of rock acoustic emission, also known as the following equation:

$$
N \propto D
$$

where $N$ is the number of $\mathrm{AE}$ events.

The rock contains different flaws within each unit, which leads to differences in the strength of the element. The units with low strength break earlier than the ones with higher strength. Also, due to the nonuniformity of the rock, the elastic modulus of the unit is not the same. Therefore, the inhomogeneity of the element leads to its rupture at different times one after another. Based on this characteristic of rocks, RFPA first takes into account the nonuniformity parameter of the material unitary in the simulation of rock acoustic emission and considers that this parameter obeys the statistical distribution law and then uses the assumption of Equation (6) to count the number of units destroyed at any time

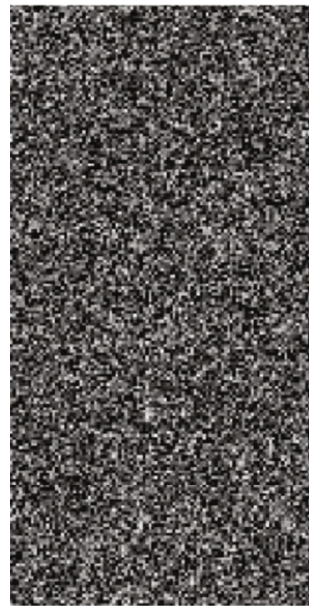

Figure 7: Numerical simulation model.

in the calculation and uses this value as a measure of rock $\mathrm{AE}$ events, which is the principle of numerical simulation of rock acoustic emission using RFPA code.

4.2. Model Establishment. The physical and mechanical parameters of sandstone measured from uniaxial compression experiments are shown in Table 1, and the RFPA code was used to conduct numerical experimental studies of acoustic emission during uniaxial compression of rocks under different stress paths. The specimen's horizontal and vertical directions were divided into 100 to 200 grids. A step-in-step calculation method was used during the test. The advantage of this method is that it can describe the damage process of the specimen in more detail, and the system automatically destabilizes and stops after the damage to the specimen without the need to set the number of computing steps artificially. The parameters of the sandstone in the numerical simulation are set in Table 2, and the established model is shown in Figure 7.

Corresponding to the standard load loading method under static applied load in the RFPA code, the basic load was set to uniaxial compression, and the loading types were realized with displacement and force to control displacement loading and control stress at one-time loading and cyclic loading and unloading, respectively.

\subsection{AE Characterization of Sandstone and Mudstone at} Different Stress Paths. The RFPA code can present the changes of $\mathrm{AE}$ of rock specimens during loading in real time. The AE of sandstone under different stress paths is shown in Figures 8-10. Each image consists of five subplots from left to right, indicating the location and intensity of AE activity during loading. In the first to fourth pictures, red circles represent $\mathrm{AE}$ events generated by tensile damage, blue circles represent $\mathrm{AE}$ events generated by shear damage, and the size 


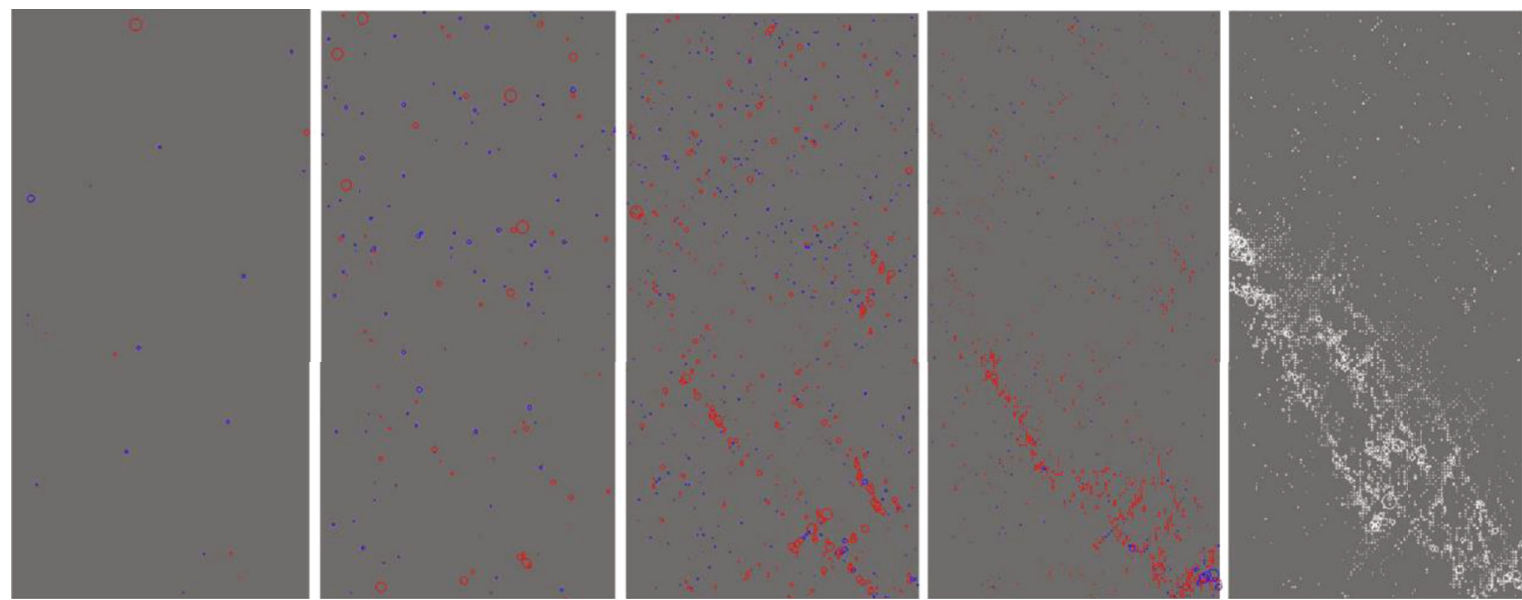

FIGURE 8: AE distribution of sandstone under controlling displacement.
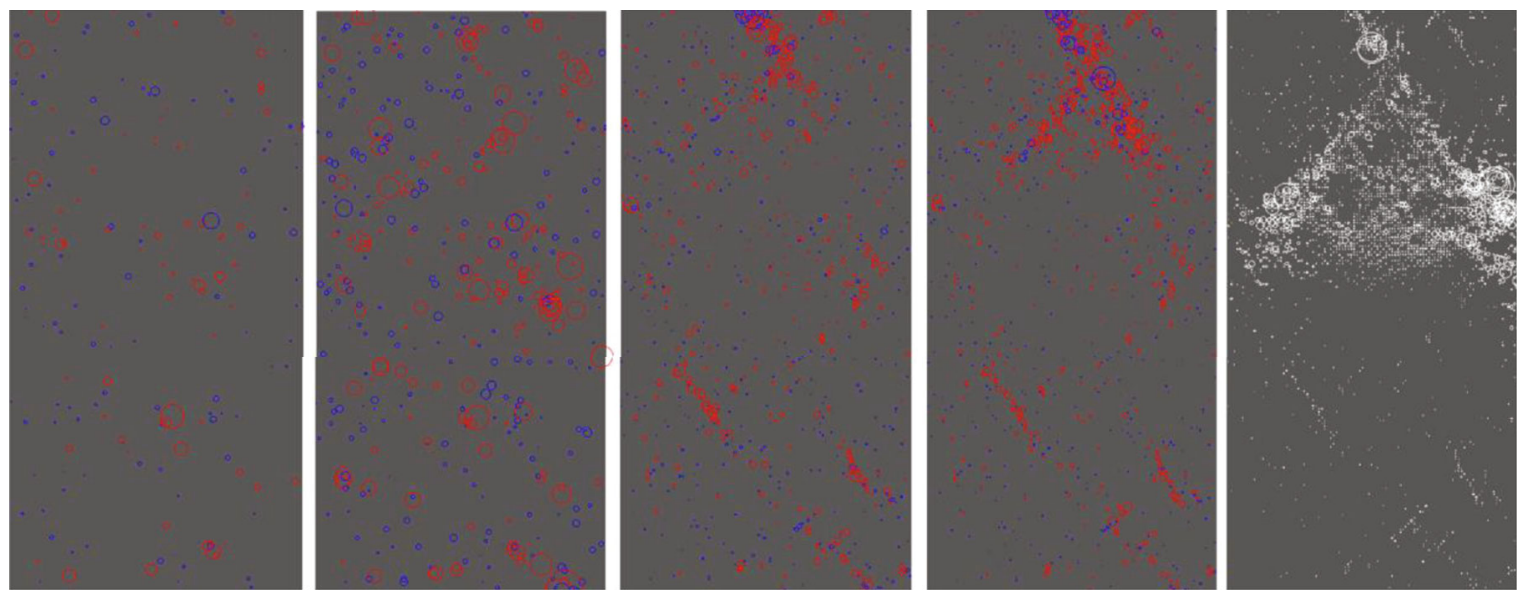

FIGURE 9: AE distribution of sandstone under controlling stress.
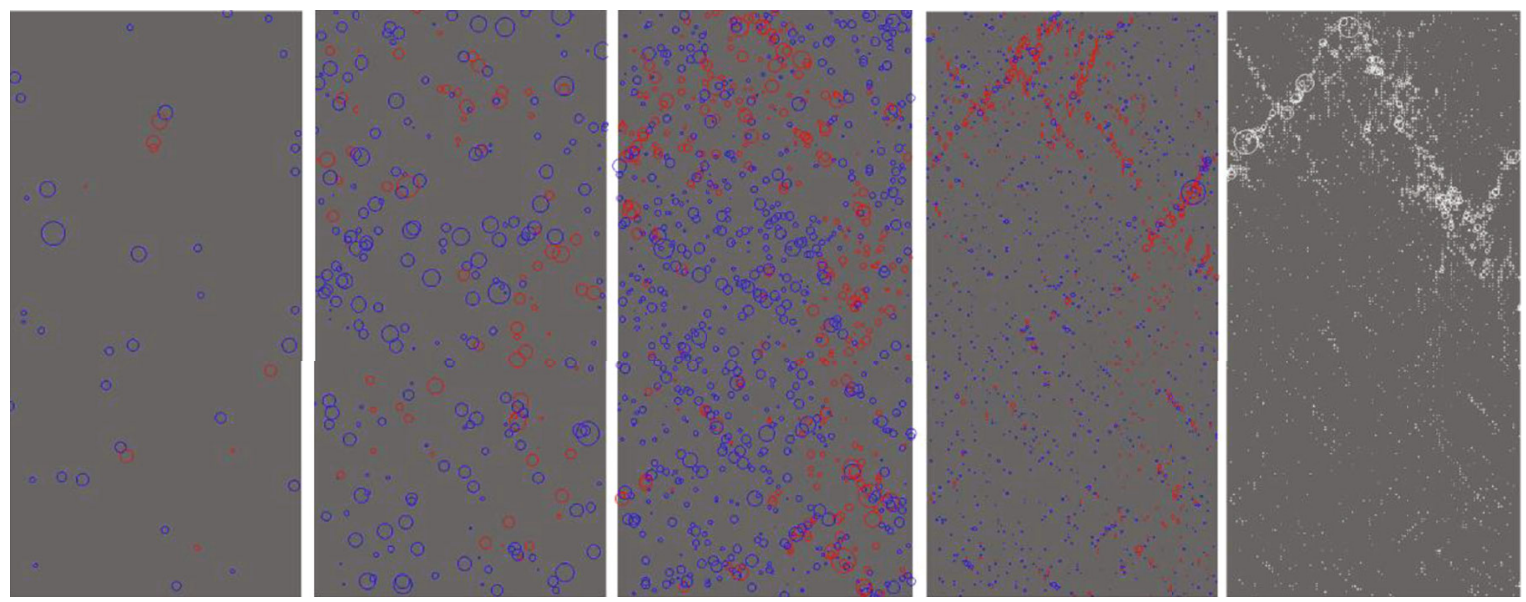

Figure 10: AE distribution of sandstone under cyclic loading and unloading.

of the circles indicates the magnitude of the AE energy, which also reflects the intensity of the AE event. In the fifth subplot, all the circles are changed to white to show more clearly the location where the rupture occurred.
As can be seen from Figures 8 and 9 , at the early stage of loading (premid compression-dense stage and elastic stage), there were fewer $\mathrm{AE}$ events, but the $\mathrm{AE}$ energy values were relatively large, and after entering the plastic stage, there 

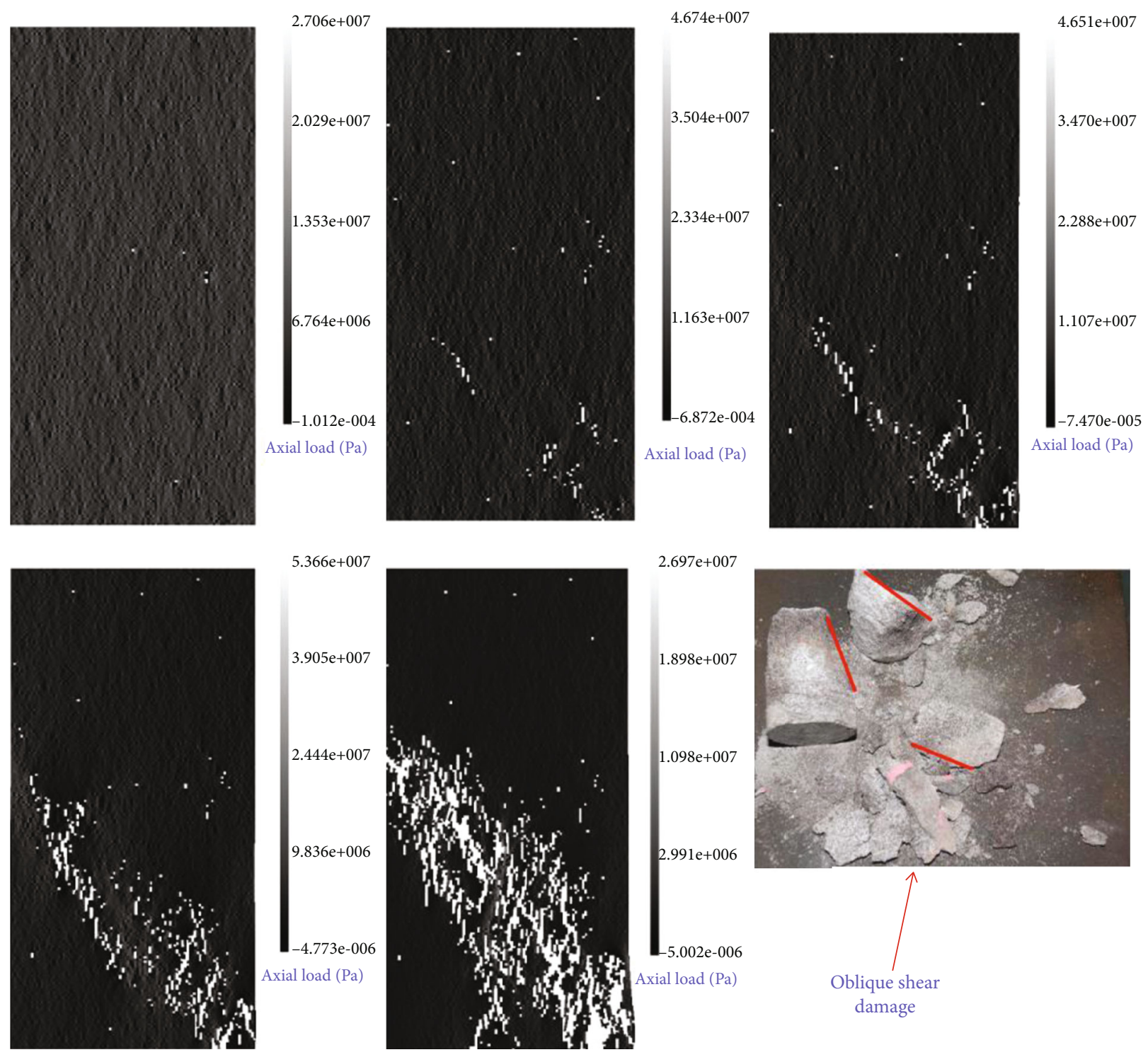

FIGURE 11: Failure process of sandstone under controlled displacement loading.

was a substantial increase in both $\mathrm{AE}$ number and AE energy. However, as the AE number increases, the AE energy does not increase exactly simultaneously but is significantly increased after it. The AE number jumped before the generation of macroscopic cracks and remains basically unchanged after the formation of fractures. As can be seen from Figure 9, there was a short period of calm where the AE number stopped increasing before a significant crack was produced. During this period, the AE number was essentially constant, which was consistent with the quiet period of acoustic emission found in the experiment. From Figure 10, it can be seen that the AE numbers of both rocks under cyclic loading and unloading were significantly higher than the first two loading methods, and the circle radius became larger and there was an increase in energy. This indicated a greater degree of damage to the sandstone under cyclic loading and unloading. From the last subplot of Figures 8-10, it showed that the AE numbers presented dense areas, which were consistent with the crack extension sites of the rocks, and the AE numbers were the highest and brighter at the sites where fracture damage occurred in the rocks, and the bright white shape formed coincided with the damage shape of the rocks, revealing the law that the location of the acoustic emission event generation and the damage destruction of the rocks were consistent.

\section{Discussion}

Loading damage analysis of the rock specimens showed that the rock was significantly more homogeneous at the beginning of loading compared to the vicinity of the peak stress. The increase in stress in each cell can be seen from the change in cell color. In the vicinity of the peak stress, the color of the unit body was obviously brighter, which indicated that the damage to the rock was mainly concentrated in the vicinity of the peak stress. Therefore, to analyze and study the damage process of the rock, the study should focus on the area around the peak stress, which was consistent with the 

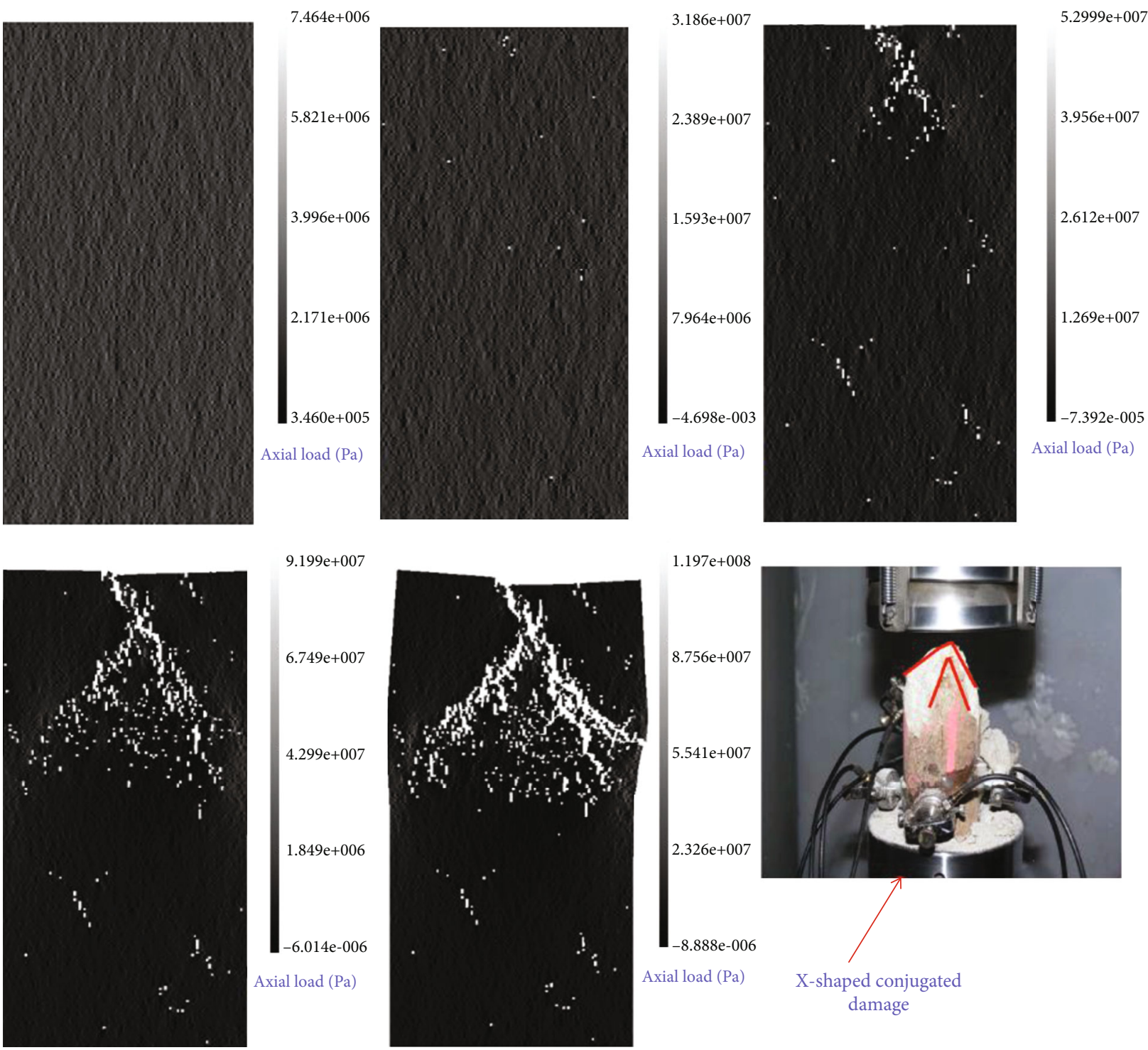

FIGURE 12: Failure process of sandstone under controlled stress loading.

conclusion that the damage to the rock under the uniaxial compression test mainly occurred in the plastic stage, as shown in Figures 11-13 for the numerical simulation of the damage process of sandstone under different stress paths.

As shown in Figure 11, when the sandstone was loaded by controlled displacement, the rock specimen initially had a more uniform color with an overall dark gray color, and then bright white spots began to be generated in the lower orientation of the rock specimen. This indicated that the tensile or shear stresses in the units near this location were high, and when the stresses in these units exceeded their strength, the units were damaged and tiny cracks appeared. With the increase in displacement, the cracks developed and diagonal cracks appeared below the specimen, and finally, an inclined damage surface was formed. That is, the sandstone occurs in an oblique shear fracture under controlled displacement for loading. From Figure 12, it can be seen that the sandstone was loaded under controlled stress for loading. The bright white spots appeared first at the upper and bottom, and with the increase in stress, the crack expansion formed cracks first at the upper part of the rock specimen, and then the cracks penetrated and formed an X-shaped conjugate oblique fracture. That is, the sandstone under controlled stress for loading occurs in an $\mathrm{X}$-shaped conjugate oblique damage. As observed in Figure 13, the sandstone showed more bright white spots at the beginning under cyclic loading and unloading, and the number was significantly higher than the first two loading methods, which indicated that the rock specimen was damaged to some extent at the beginning. After unloading and reloading, the bright white color tends to increase, and first, tiny bright white cracks are formed in the upper part of the rock mass. In the process of repeated loading and unloading, the top cracks developed and extended to the middle and lower parts and finally formed penetrating cracks, and the direction was parallel to the axial direction of the rock mass. That is, the sandstone under cyclic loading and unloading occurs vertical splitting tensile fracture. 
$1.144 \mathrm{e}+009$

$2.022 \mathrm{e}+009$

$2.313 e+009$
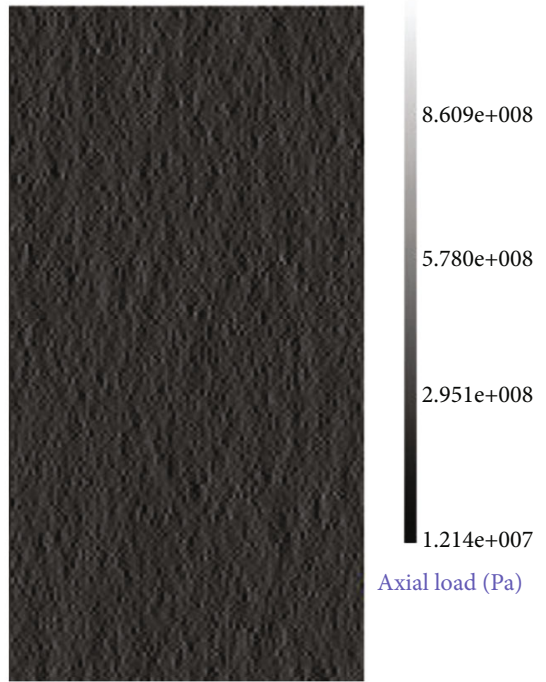

Axial load (Pa)
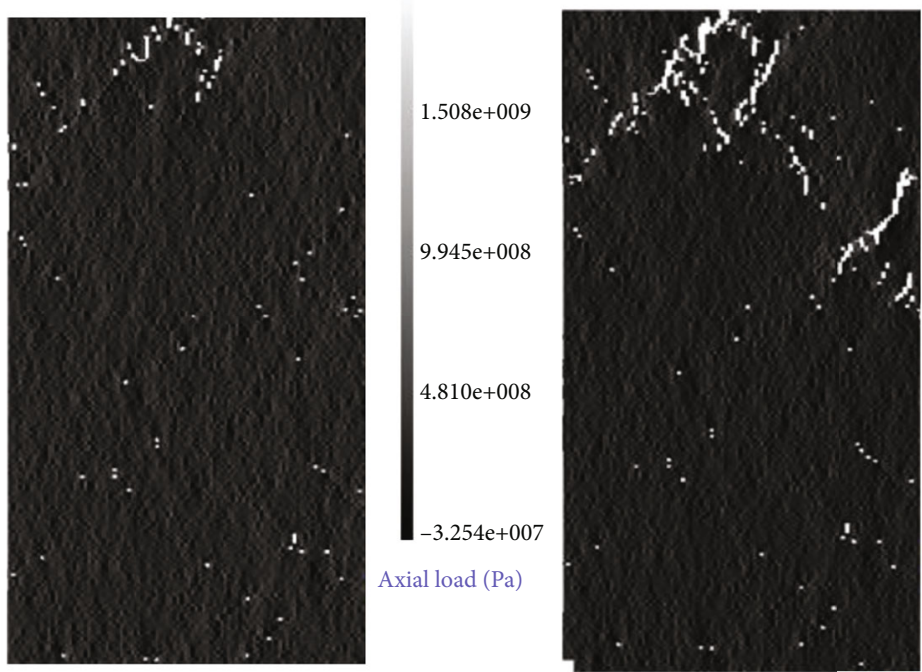

$1.723 e+009$

Axial load $(\mathrm{Pa})$

$1.377 e+009$

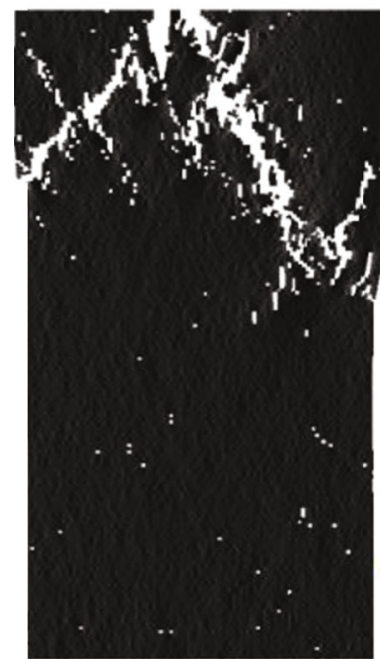

$2.517 \mathrm{e}+009$
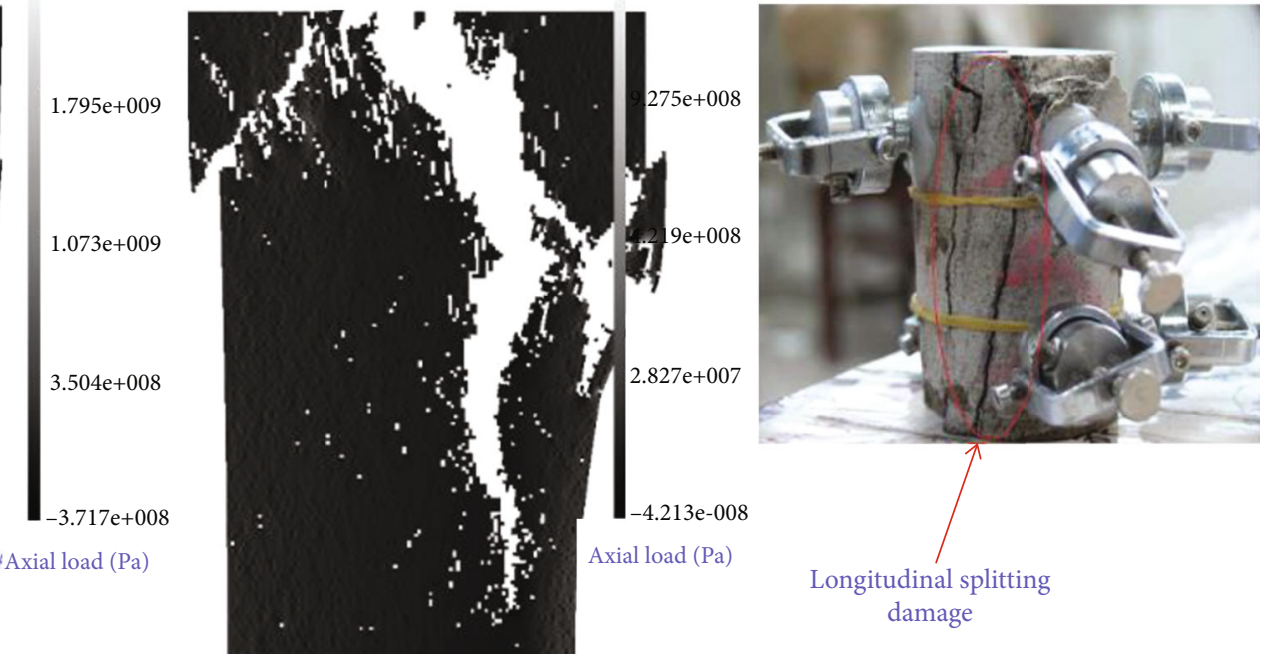

FIGURE 13: Failure process of sandstone under the controlled stress cyclic loading and unloading.

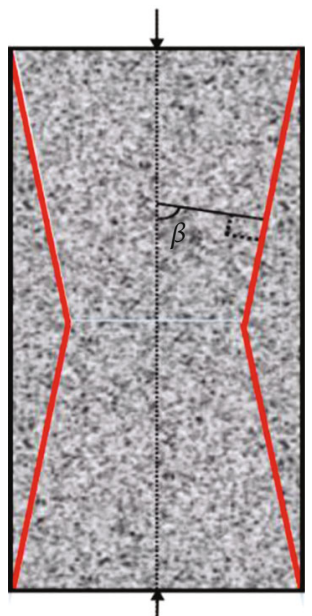

(a)

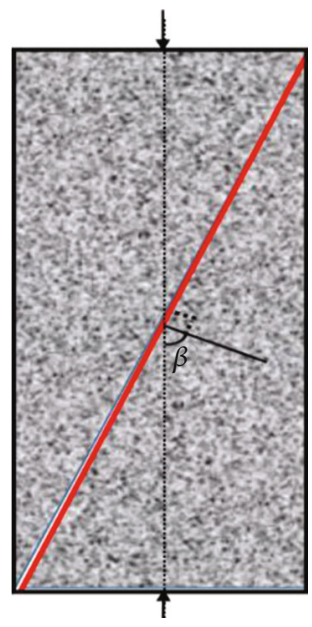

(b)

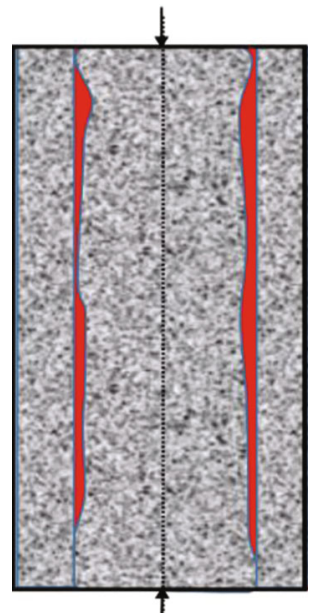

(c)

FIGURE 14: The failure modes of rock under uniaxial compression: (a) X-shaped conjugate oblique fracture, (b) oblique shear fracture, and (c) vertical splitting tensile fracture. 
The damage modes of rock specimens under uniaxial compression can be classified into three categories, as shown in Figure 14.

$\mathrm{X}$-shaped conjugate oblique shear breakage, as in Figure 14(a). The normal to the breaking surface and the axial load are at an angle of $\beta$. It can be expressed as

$$
\beta=\frac{\pi}{4}+\frac{\varphi}{2}
$$

where $\beta$ is the angle between the normal of the damage surface and the axial load and $\varphi$ is the angle of internal friction of the rock.

This mode of damage was caused by the shear stress on the damaged surface exceeding the shear strength of the rock, resulting in shear damage to the rock. As shown in Figure 12, $\mathrm{X}$-shaped conjugate oblique fracture occurred when controlled stress was applied. Single oblique shear damage is shown in Figure 14(b). This pattern of damage was also caused by the shear stress on the damaged surface exceeding the shear strength, but the maximum shear stress applied to the damaged surface before the specimen was damaged was related to the normal stress on the damage surface, so it is also called compression-shear damage. As in Figure 11, the specimen showed oblique fracture damage when the controlled displacement was loaded, which belongs to compression-shear damage. Longitudinal tensile fracture is shown in Figure 14(c). This mode of fracture was due to the axial load acting on the rock specimen. Owing to the Poisson effect, tensile stresses were generated in the lateral direction of the specimen, and when the lateral tensile stress was greater than the tensile limit of the rock, the specimen was damaged. As shown in Figure 13, under cyclic loading and unloading conditions, the specimen showed tensile damage with longitudinal splitting, and the acoustic emission point matched the rock crack damage shape.

\section{Conclusions}

The differences in acoustic emission characteristics and damage modes of sandstone during the damage process are analyzed by uniaxial compression failure experiments under different stress paths in the laboratory and numerical simulation studies using the RFPA code. The main conclusions are as follows:

(1) The maximum value of AE events in sandstones is at the peak of the rock, and AE activity is the most intense at the peak of stress. Peak AE energy is earlier than peak $\mathrm{AE}$ events

(2) When the sandstone is loaded with different stress loading methods, the rock specimens initially have a more uniform color with an overall dark gray color, and then bright white spots begin to be generated in the rock specimens. This is a result of the high shear stress in the units near this location, and when the shear stress in these units exceeds the shear strength, the units are damaged and tiny cracks appear. As the displacement increases, the cracks develop and penetrate, and the specimen is fractured

(3) The damage pattern of the rock is related to the way the stress is loaded, and the fragmentation size is also influenced by the loading method. The fragmentation size of sandstone when loading is performed by controlled stress is much smaller than when loading by controlled displacement. Both experiments and numerical simulations found a momentary state of quiescence where the $\mathrm{AE}$ number of the sandstone stops increasing before significant cracking occurs, i.e., a period of $\mathrm{AE}$ calm

(4) Under cyclic loading and unloading, the number of AE events increases significantly compared with the controlled displacement and controlled stress loading methods, and the radius of the circle becomes larger and there is an increase in AE energy, which indicates a greater degree of destruction under cyclic loading and unloading. The place where the number of $\mathrm{AE}$ events shows a dense pattern indicates that the rock is cracked, concentrated, and prone to extensional fracture at that site. The maximum number of $\mathrm{AE}$ events and the brighter the color in the part of the rock where the fracture damage occurs, the more the bright white shape formed matches the shape of the damage to the rock

\section{Data Availability}

The data used to support the findings of this study are available from the corresponding author upon request.

\section{Conflicts of Interest}

The authors declare that they have no conflict of interest.

\section{Acknowledgments}

This paper is supported by the Fundamental Research Funds for the Central Universities (2020ZDPYZD02).

\section{References}

[1] Z. He, K. Zhao, Y. Yan, F. Ning, Y. Zhou, and Y. Song, "Mechanical response and acoustic emission characteristics of cement paste backfill and rock combination," Construction and Building Materials, vol. 288, p. 123119, 2021.

[2] T. Bruning, M. Karakus, G. D. Nguyen, and D. Goodchild, "Experimental study on the damage evolution of brittle rock under triaxial confinement with full circumferential strain control," Rock Mechanics and Rock Engineering, vol. 51, no. 11, pp. 3321-3341, 2018.

[3] T. Xu, M. Fu, S.-q. Yang, M. J. Heap, and G.-l. Zhou, “A numerical meso-scale elasto-plastic damage model for modeling the deformation and fracturing of sandstone under cyclic loading," Rock Mechanics and Rock Engineering, pp. 1-23, 2021.

[4] X. Liu, L. Wu, Y. Zhang, S. Wang, X. Yao, and X. Wu, "The characteristics of crack existence and development during rock 
shear fracturing evolution," Bulletin of Engineering Geology and the Environment, vol. 80, no. 2, pp. 1671-1682, 2021.

[5] H. Odegaard and B. Nilsen, "Rock stress measurements for unlined pressure tunnels: a true triaxial laboratory experiment to investigate the ability of a simplified hydraulic jacking test to assess fracture normal stress," Rock Mechanics and Rock Engineering, vol. 54, no. 6, pp. 2995-3015, 2021.

[6] L. Shengxiang, X. Qin, L. Xiling, L. Xibing, L. Yu, and C. Daolong, "Study on the acoustic emission characteristics of different rock types and its fracture mechanism in Brazilian splitting test," Frontiers in Physics, vol. 9, 2021.

[7] T. Ishida, S. Desaki, Y. Kishimoto, M. Naoi, and H. Fujii, "Acoustic emission monitoring of hydraulic fracturing using carbon dioxide in a small-scale field experiment," International Journal of Rock Mechanics and Mining Sciences, vol. 141, p. 104712, 2021.

[8] Z. Zhou, S. Chen, Y. Wang, and Z. Dai, "Crack evolution characteristics and cracking mechanism of red beds in Central Sichuan during seepage and swelling," Geofluids, vol. 2021, Article ID 9981046, 19 pages, 2021.

[9] M. T. W. Schimmel, S. J. T. Hangx, and C. J. Spiers, "Impact of chemical environment on compaction behaviour of quartz sands during stress-cycling," Rock Mechanics and Rock Engineering, vol. 54, no. 3, pp. 981-1003, 2021.

[10] D. Liang, N. Zhang, L. Xie, G. Zhao, and D. Qian, "Damage and fractal evolution trends of sandstones under constantamplitude and tiered cyclic loading and unloading based on acoustic emission," International Journal of Distributed Sensor Networks, vol. 15, no. 7, 2019.

[11] Y. Wang, J. Q. Han, and C. H. Li, “Acoustic emission and CT investigation on fracture evolution of granite containing two flaws subjected to freeze-thaw and cyclic uniaxial increasingamplitude loading conditions," Construction and Building Materials, vol. 260, article 119769, 2020.

[12] H. Sun, L. Ma, W. Liu, A. J. S. Spearing, J. Han, and Y. Fu, “The response mechanism of acoustic and thermal effect when stress causes rock damage," Applied Acoustics, vol. 180, article 108093, 2021.

[13] K. Zhao, D. Yang, P. Zeng, C. Gong, X. Wang, and W. Zhong, "Accelerating creep stage of red sandstone expressed and quantitatively identified based on acoustic emission information," Rock Mechanics and Rock Engineering, 2021.

[14] J. Lu, G. Yin, D. Zhang, H. Gao, C. Li, and M. Li, "True triaxial strength and failure characteristics of cubic coal and sandstone under different loading paths," International Journal of Rock Mechanics and Mining Sciences, vol. 135, p. 104439, 2020.

[15] M. Kharghani, K. Goshtasbi, M. Nikkah, and K. Ahangari, "Investigation of the Kaiser effect in anisotropic rocks with different angles by acoustic emission method," Applied Acoustics, vol. 175, p. 107831, 2021.

[16] J. Li, J. Zhao, S. Y. Gong et al., "Mechanical anisotropy of coal under coupled biaxial static and dynamic loads," International Journal of Rock Mechanics and Mining Sciences, vol. 143, p. $104807,2021$.

[17] P. M. Benson, D. C. Austria, S. Gehne et al., "Laboratory simulations of fluid-induced seismicity, hydraulic fracture, and fluid flow," Geomechanics for Energy and the Environment, vol. 24, p. 100169, 2020.

[18] A. Butcher, A. L. Stork, J. P. Verdon et al., "Evaluating rock mass disturbance within open-pit excavations using seismic methods: a case study from the Hinkley point $\mathrm{C}$ nuclear power station," Journal of Rock Mechanics and Geotechnical Engineering, vol. 13, no. 3, pp. 500-512, 2021.

[19] W. Cai, L. Dou, M. Zhang, W. Cao, J. Q. Shi, and L. Feng, “A fuzzy comprehensive evaluation methodology for rock burst forecasting using microseismic monitoring," Tunnelling and Underground Space Technology, vol. 80, pp. 232-245, 2018.

[20] G. Dresen, G. Kwiatek, T. Goebel, and Y. Ben-Zion, "Seismic and aseismic preparatory processes before large stick-slip failure," Pure and Applied Geophysics, vol. 177, no. 12, pp. 57415760, 2020.

[21] Y. V. Marapulets and A. O. Shcherbina, "Assessing the orientation of the axis of maximum compression of rocks with a combined point receiver system," Acoustical Physics, vol. 64, no. 6, pp. 742-749, 2018.

[22] J. Zhang, C. Ai, Y. W. Li, M. G. Che, R. Gao, and J. Zeng, "Energy-based brittleness index and acoustic emission characteristics of anisotropic coal under triaxial stress condition," Rock Mechanics and Rock Engineering, vol. 51, no. 11, pp. 3343-3360, 2018.

[23] A. Davarpanah, R. Shirmohammadi, B. Mirshekari, and A. Aslani, "Analysis of hydraulic fracturing techniques: hybrid fuzzy approaches," Arabian Journal of Geosciences, vol. 12, no. 13, p. 402, 2019.

[24] A. Damani, C. H. Sondergeld, and C. S. Rai, "Experimental investigation of in situ and injection fluid effect on hydraulic fracture mechanism using acoustic emission in Tennessee sandstone," Journal of Petroleum Science and Engineering, vol. 171, pp. 315-324, 2018.

[25] D. Liang, N. Zhang, H. Rong, and Z. Xiang, "Experimental and numerical studies on crack initiation and coalescence in sandy mudstone with prefabricated cross-flaws under uniaxial compression," Shock and Vibration, vol. 2021, Article ID 6672913, 17 pages, 2021.

[26] D. Liang, N. Zhang, H. Liu, D. Fukuda, and H. Rong, "Hybrid finite-discrete element simulator based on GPGPU-parallelized computation for modelling crack initiation and coalescence in sandy mudstone with prefabricated cross-flaws under uniaxial compression," Engineering Fracture Mechanics, vol. 247, article 107658, 2021.

[27] C. Tang, "Numerical simulation of progressive rock failure and associated seismicity," International Journal of Rock Mechanics and Mining Sciences, vol. 34, no. 2, pp. 249-261, 1997.

[28] C. E. Fairhurst and J. A. Hudson, "Draft ISRM suggested method for the complete stress-strain curve for intact rock in uniaxial compression," International Journal of Rock Mechanics \& Mining Science \& Geomechanics Abstracts, vol. 36, no. 3, pp. 281-289, 1999.

[29] T. F. Wong, R. H. C. Wong, K. T. Chau, and C. A. Tang, "Microcrack statistics, Weibull distribution and micromechanical modeling of compressive failure in rock," Mechanics of Materials, vol. 38, no. 7, pp. 664-681, 2006. 